\title{
State and Origin of Present-Day Stress Fields in Sedimentary Basins
}

\author{
Mark Tingay* \\ Department of Applied Geology, Curtin University of Technology, Perth, \\ m.tingay@curtin.edu.au.
}

Key Words: Stress, Sedimentary Basins, Petroleum Geomechanics

\begin{abstract}
The present-day stress field provides fundamental insight into the forces driving plate tectonics and intra-plate deformation. Furthermore, Knowledge of the present-day stress field is essential in petroleum, geothermal and mining geomechanics applications such as the stability of boreholes and tunnels, and improving production through natural and induced fractures. The World Stress Map (WSM) Project has, for over 20 years, compiled a public global database of present-day tectonic stress information to determine and understand the state of stress in the Earth's lithosphere. The WSM database has revealed that plate-scale stress fields are controlled by forces exerted at plate boundaries (e.g. mid-ocean ridges, continental collision zones), commonly resulting in regional stress orientations sub-parallel to plate motion. However, the state and origin of present-day stress fields at smaller scales, such as within sedimentary basins, remains poorly understood in comparison. Detailed analysis of present-day stresses from within 70 sedimentary basins commonly reveals significant and complex variations in the present-day stress orientation, both across basins and within fields. For example, borehole breakouts in the North German Basin, Nile Delta and the Baram Delta province of northwest Borneo indicate broad regional rotations in the horizontal stress orientation. The present-day maximum horizontal stress orientations in the Gulf of Thailand are approximately north-south at the basinscale (perpendicular to plate motion) and are perturbed locally to be sub-parallel to fault strike. The North Sea and Permian Basin of Texas display widely varying stress orientations between fields, with some neighbouring fields exhibiting perpendicular stress orientations. Basin- and field-scale stress fields result from the complex combination of numerous factors acting at different scales, including far-field forces (e.g. plate boundary forces), basin geometry (e.g. the shape of deltaic wedges), geological structures (e.g. diapirs, faults), mechanical contrasts (e.g. evaporites, overpressured shales, detachment zones), topography and deglaciation.
\end{abstract}

\section{INTRODUCTION}

The last 20 years has seen a dramatic increase in the use of present-day stress data for issues affecting petroleum exploration and production. The orientation of contemporary maximum horizontal stress $\left(\mathrm{S}_{\mathrm{H} \max }\right)$ is of particular importance as it is a major influence on:

- the geometry of hydraulic fractures (Hubbert \& Willis, 1957);

- the direction of preferential fluid flow in EOR operations (Heffer \& Lean, 1993);

- seal breach caused by fault reactivation (Finkbeiner et al. 2001), and;

- the mechanical stability of boreholes (Aadnoy \& Chenevery, 1987).

The World Stress Map (WSM) project has compiled an extensive database of $\mathrm{S}_{\mathrm{Hmax}}$ orientations from borehole breakouts and drilling-induced fractures in over 4000 wells from over than 70 sedimentary basins worldwide (Figure 1; Tingay et al., 2005; Heidbach et al., 2008). This extensive dataset is the combined work of dozens of researchers conducting local and basinscale stress analysis. This study aims to compile the key aspects of these studies, combined with new data collected as part of the WSM Present-day Stress in Sedimentary Basins initiative, to summarize the key controls on the present-day stress orientation in sedimentary basins. 


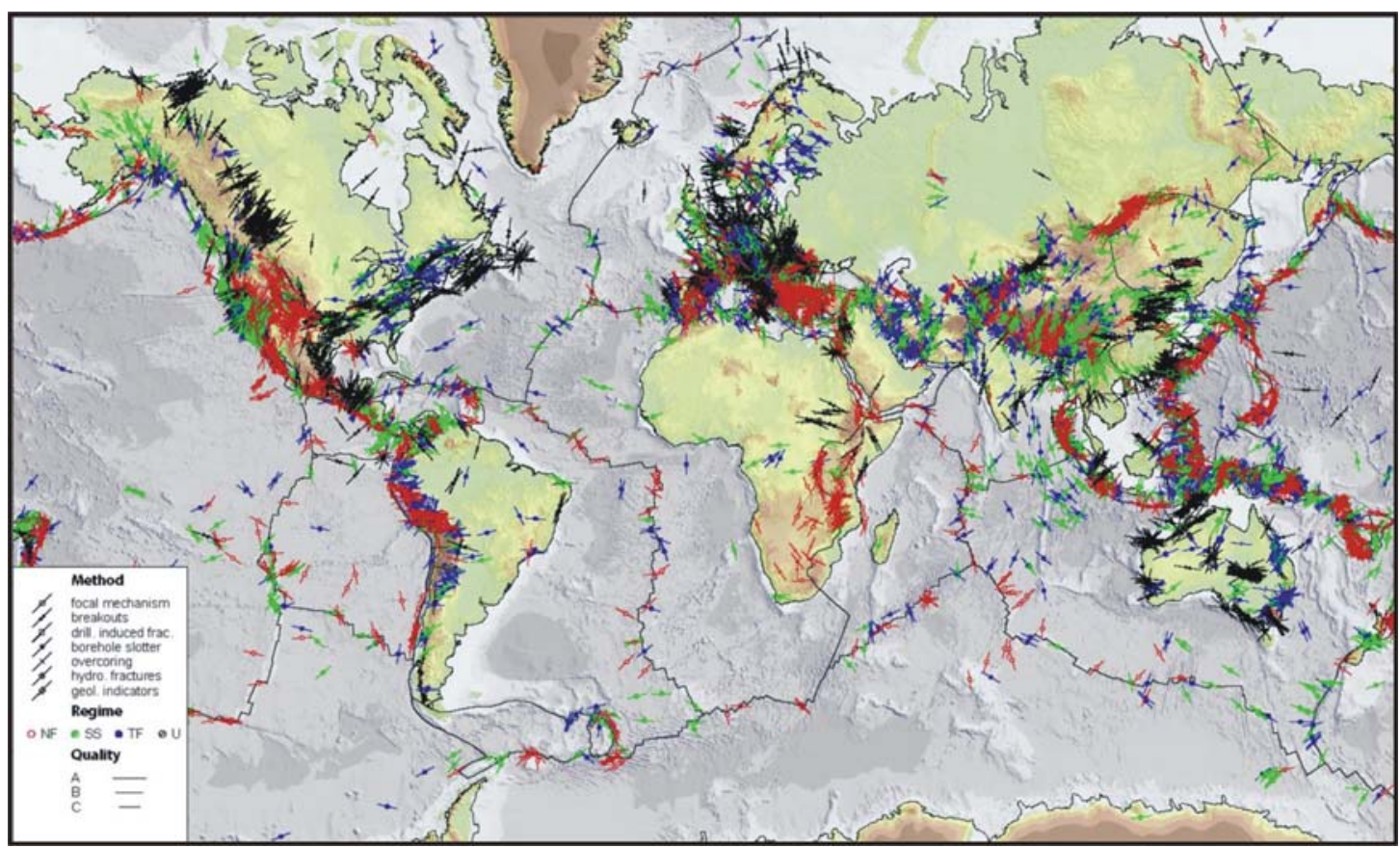

Figure 1: The World Stress Map consisting of over 14000 A-C quality stress indicators from a variety of stress measurement techniques. NF: Normal faulting stress regime (red), SS: Strikeslip (green), TF: Thrust fault (blue), U: undefined (black) (see legend for more details on symbols).

\section{FAR-FIELD FORCES}

The WSM project has revealed fundamental insights into the state and forces controlling largescale stress fields (plate-scale, and regional scales with wave lengths of greater than $500 \mathrm{~km}$ ). The first WSM Project release demonstrated that the maximum horizontal stress orientations in North America, South America and Europe are, at the plate-scale, predominately oriented subparallel to absolute plate motions (Richardson, 1992; Zoback, 1992). The correlation of stresses and plate motions suggests that the first-order intra-plate stress field is the result of forces generated at plate boundaries, primarily mid-ocean ridge 'push', subducting slab 'pull', trench 'suction' and traction at the base of the lithosphere (Figure 2; Zoback, 1992). Examination of more complex plates (such as the Indo-Australian Plate) and of stresses proximal to mountain ranges and subduction zones has revealed that continental collision and large intra-plate forces such as isostatic compensation, lithospheric flexure and large topographic forces have an additional major impact on the large-scale lithospheric stress field (Figure 2; Hillis and Reynolds, 2000; Tingay et al., 2005).

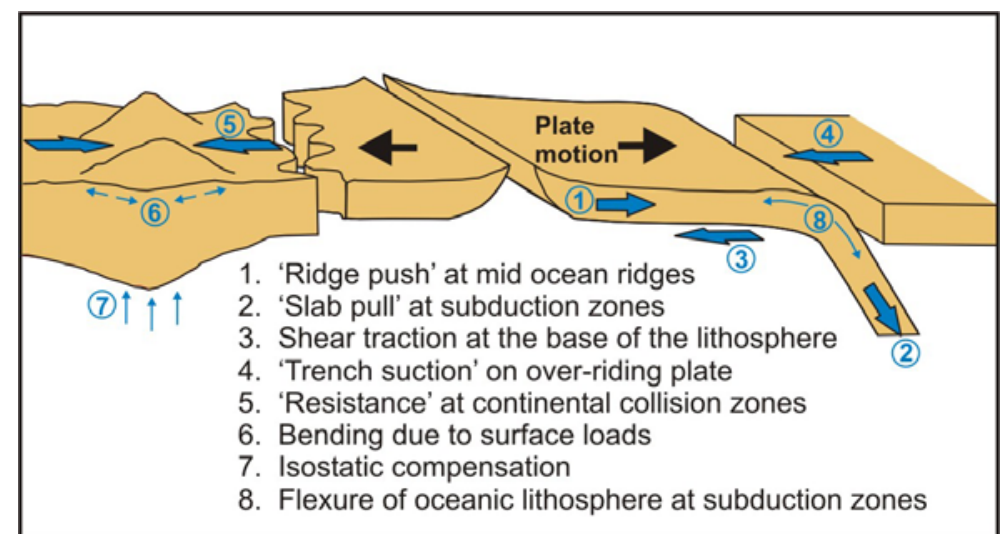

Figure 2: Forces controlling the present-day tectonic stress field at the 'primary' plate-scale (large blue arrows) and 'secondary' broad regional scales (small blue arrows; adapted from Zoback, 1992). 
The plate boundary and large intra-plate sources of stress are, by far, the main forces controlling the intra-plate stress field - and, thus, the stress field in the basement rocks directly underlying sedimentary basins. Hence, the stress fields in sedimentary basins are commonly observed to be very similar to the primary or secondary lithospheric stress fields. For example, the modelled correlation between the observed stress orientations in Australian sedimentary basins and the stress field predicted by primary and secondary sources of stress, and the broad fan-shaped stress field in the North German Basin resulting from plate boundary forces and 'pinning' of the Trans European Suture Zone (Figure 3; Roth and Fleckenstein, 2000; Reynolds et al., 2002; Tingay et al., 2005). Hence, the primary and secondary sources of stress typically provide the regional or 'background' stress field upon which stresses resulting from other, smaller, sources of stress are superimposed (Bell, 1996).

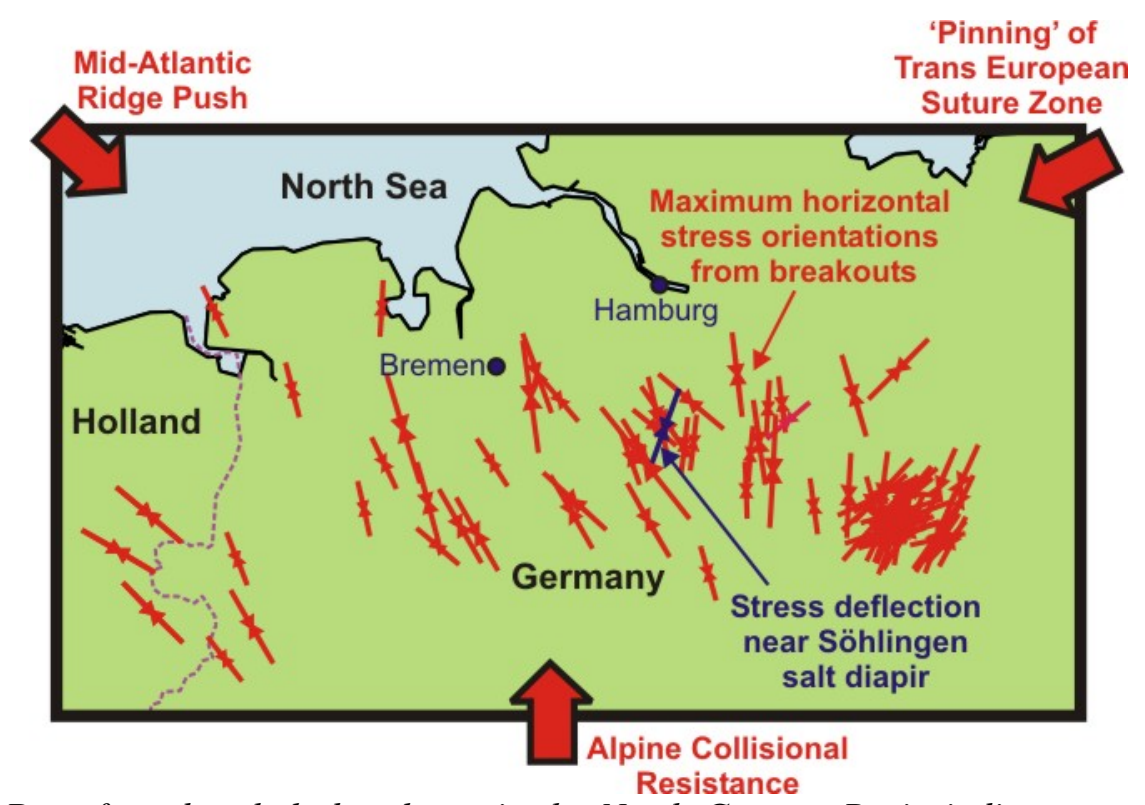

Figure 3: Data from borehole breakouts in the North German Basin indicate a regional 'fan shaped' stress pattern, with $S_{\text {Hmax }}$ orientations trending from NW-SE in the west to N-S and NESW in the east (Roth and Fleckenstein, 2001; Tingay et al., 2005). The regional stress rotation is believed to be the result of a complex interaction between far-field forces exerted by the Alpine front, mid-Atlantic ridge and 'pinning' of the Trans-European Suture Zone (Tingay et al., 2005). Stress orientations are also locally rotated in the vicinity of salt diapirs, such as near the Söhlingen diapir (in blue).

\section{BASAL AND INTRABASINAL DETACHMENT}

The comparative influence of plate boundary forces and 'local' intra-basin forces on the stress field in sedimentary basins is a function of their relative magnitudes and orientations. In general, the far-field stresses have much greater magnitudes than 'local' stresses and dominate the stress field. However, the influence of the stronger, far field stresses (acting in the basement) can be partially or totally removed from the stresses acting in the overlying sedimentary sequences by deep mechanical detachment zones. Hence, basins that contain some form of basal detachment zone typically exhibit complicated stress patterns due to the dominance of smaller intra-basin sources of stress, whereas basins that are mechanically attached to the basement typically display regionally consistent stress fields resulting from far-field forces (Figure 4; Bell, 1996). 

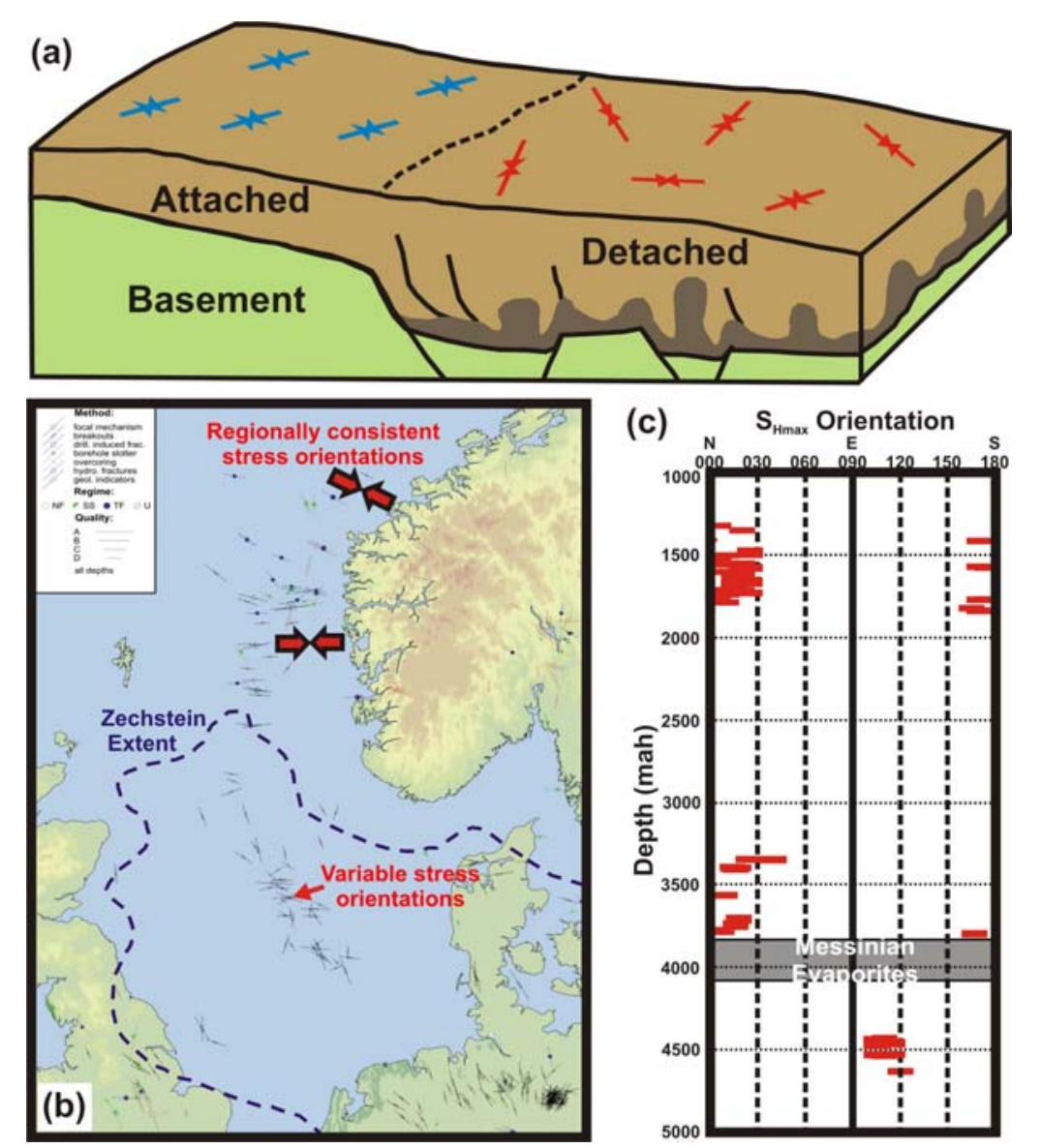

Figure 4: (a) Schematic diagram of stress orientations in regions that are mechanically attached (on the left) or detached from the basement (on the right; after Bell, 1996). Attached regions commonly exhibit consistent stress orientations (blue symbols), generally in line with the broad regional or plate-scale stress field. Stresses in the detached regions are controlled by smaller-scale sources of stress and commonly exhibit highly varied and complex stress orientations (red symbols). Sources of detachment include evaporite layers, overpressured shales or mechanically 'weak' sub-horizontal faults. (b) This scenario is observed in the North Sea, where consistent stress orientations are observed in the 'attached' northern North Sea and scattered orientations in the 'detached' central North Sea. The scattered stress orientations in the central North Sea are in sequences overlying the Z2 Zechstein evaporites, suggesting that the Zechstein formation is acting as a regional detachment zone (adapted from Ask, 1997 and Hillis \& Nelson, 2006). (c) Detachment horizons may also be intrabasinal. $S_{\text {Hmax }}$ orientations observed from borehole breakouts and drilling-induced fractures indicate a ESE-WNW $S_{\text {Hmax }}$ orientation below Messinian evaporite sequences in the eastern Nile Delta. However, NNE-SSW $S_{\text {Hmax }}$ orientations are observed in sequences overlying the Messinian evaporites.

Basal detachment zones occur due to the presence of mechanically 'weak' or ductile material that is unable to effectively transmit shear stresses from the rocks below the detachment into overlying sequences. Basal detachment zones in sedimentary basins typically include evaporite horizons, sequences of highly overpressured shale and low angle fault zones (particularly fault zones containing high magnitude overpressures; Bell, 1996). Hence, detachment zones may act regionally, when detachment horizons are basin-wide (e.g. overpressured prodelta shales), or over small regions if the detachment surface is only locally present (e.g. faults, localized evaporites). Excellent examples of stress variations are observed in the North Sea, where complex stress patterns are observed in sequences overlying the Zechstein evaporites (Ask, 1997; Hillis \& Nelson, 2006), and the Nile Delta, where different stress orientations are observed above and below the Messinian evaporites (Figure 4). 

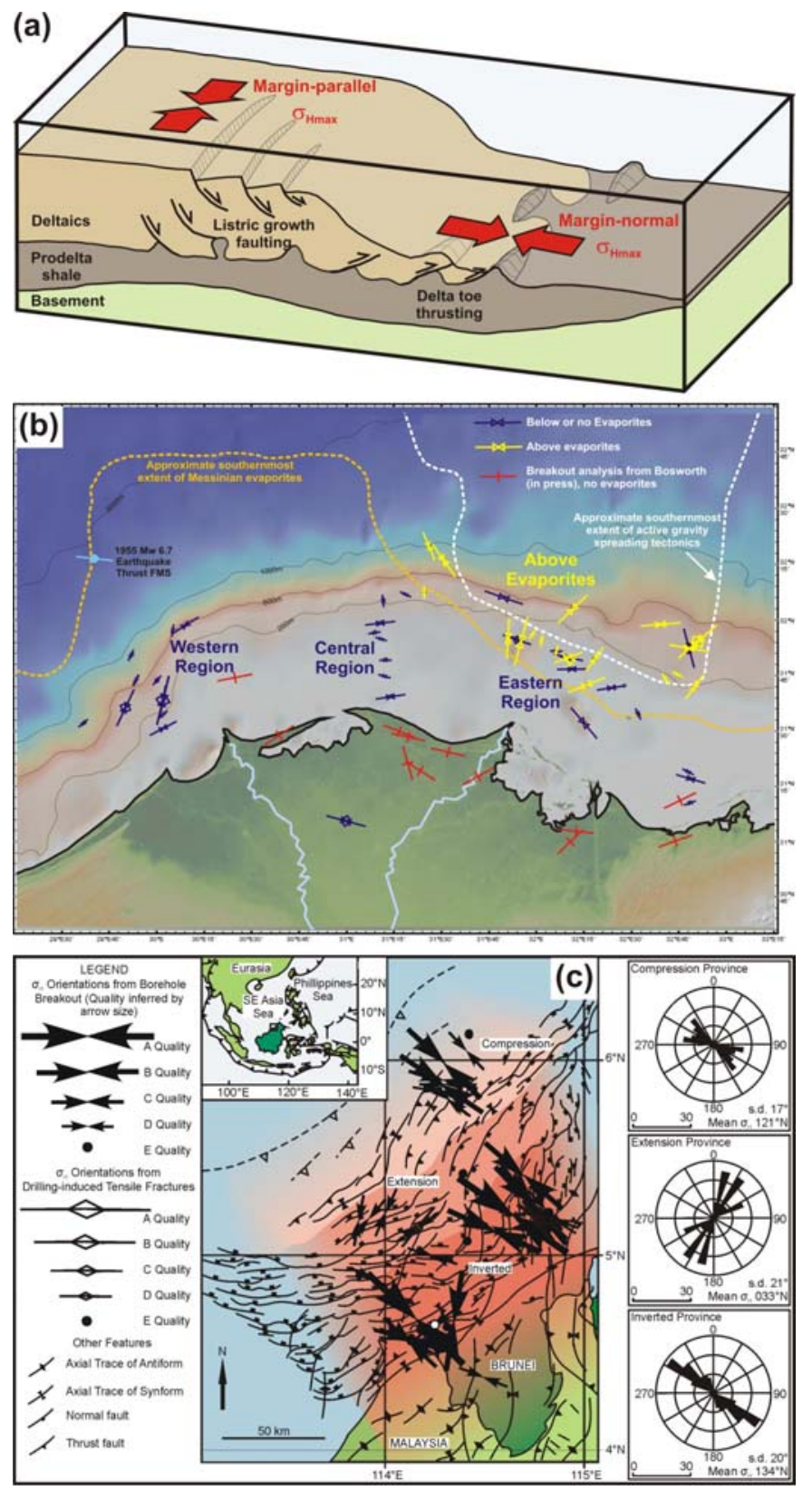

Figure 5: (a) Schematic relationship between present-day stress and structures in passivemargin Tertiary deltas (after Tingay et al., 2005). (b) Present-day $S_{\text {Hmax }}$ orientations in the Nile Delta. $S_{H \max }$ orientations are largely parallel to the coastline in regions absent or below the Messinian evaporites (blue and red symbols). However, $S_{\text {Hmax }}$ orientations are variable though predominately margin normal in sequences overlying the Messinian evaporites (yellow symbols). Symbol length represents stress orientation quality (reliability). (c) Stress orientations in the Baram Delta, NW Borneo. The $S_{H \max }$ orientation is NW-SE (margin-normal) in the inverted inboard parts of the delta, NE-SW (margin-parallel) in the region of active extension at the shelf edge, but rotates to NW-SE (margin-normal) in the delta toe (after King et al., in press).

\section{BASIN GEOMETRY (PARTICULARLY TERTIARY DELTAS)}

Gravitational forces acting on basin geometry (herein the surface, sub-sea or basement 'topography') can cause a variation in stress orientations due to either the earth's surface acting as a free surface and/or due to lateral density contrasts. The effect of gravitational forces on basin geometry is particularly highlighted in Tertiary deltas, such as in the Nile and Baram Deltas (Figure 5). Tertiary deltas often contain widespread mobile evaporite sequences and/or thick overpressured (and mobile) prodelta shale sequences that act as regional basal detachment 
zones. The convex-upwards deltaic 'wedge', in combination with a basin-wide basal detachment zone, promotes basinward-oriented gravitational extension on the shelf, that results in a margin-parallel maximum horizontal stress orientation and associated margin-parallel striking growth faults (Figure 5; Tingay et al., 2005). This convex-upwards deltaic geometry also results in margin-normal compression and associated folding and thrust faulting at the delta toe, and thus also results in a margin-normal maximum horizontal stress orientations in the delta toe (Figure 5; Tingay et al., 2005; King et al., in press).

\section{MAJOR TOPOGRAPHY (PARTICULARLY FORELAND BASINS)}

Gravitational forces acting on mountain ranges promote lateral extension within the mountain range and compression in surrounding regions. Hence, the stress field near mountain ranges is typically characterized by $S_{H \max }$ orientations oriented parallel to the topographic front within mountain belts, but $S_{H \max }$ orientations perpendicular to the topographic front in surrounding areas, such as foreland basins. Indeed, the present-day $S_{\mathrm{Hmax}}$ orientation in foreland basins, such as the Molasse Basin, Alberta Basin and Neuquén Basin, is typically highly uniform and oriented perpendicular to the topographic front (Figure 6).

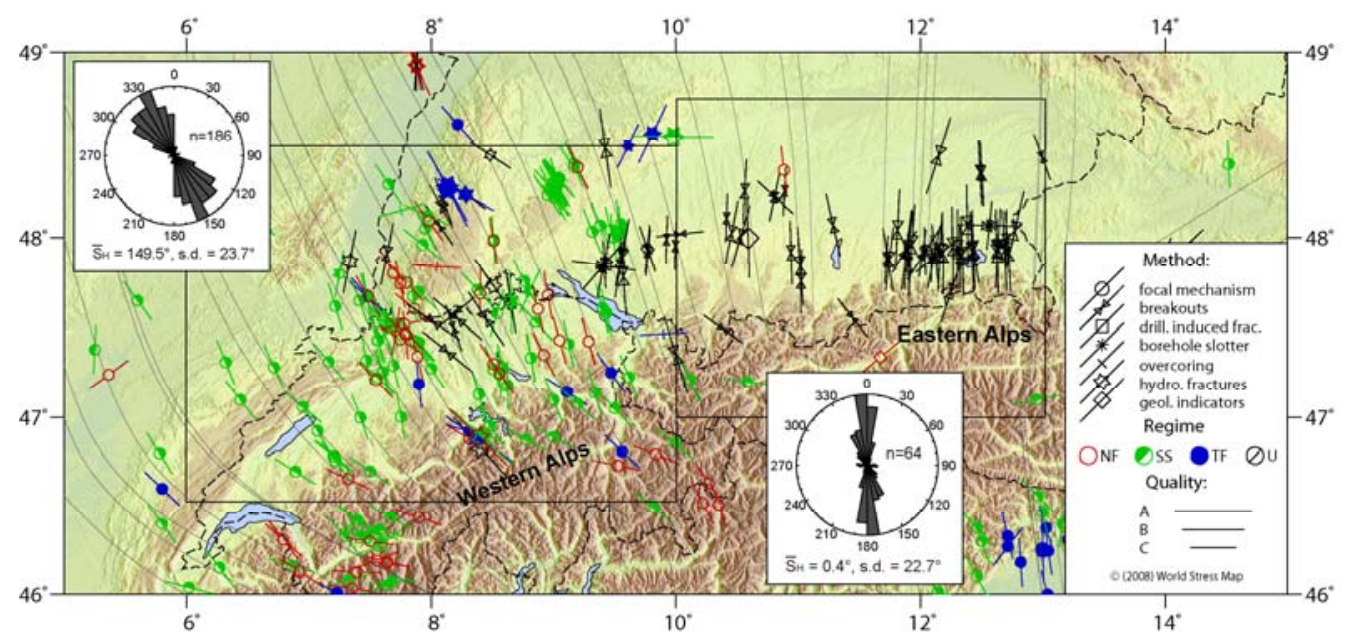

Figure 6: Present-day $S_{\text {Hmax }}$ orientations in the Molasse Basin from borehole breakouts, drilling-induced fractures and earthquake focal mechanism solutions. $S_{\text {Hmax }}$ rotates from $\mathrm{N}$-S in the Eastern Alps $\left(000^{\circ} \mathrm{N} \pm 23^{\circ}\right)$ to NNW-SSE in the Western Alps $\left(150^{\circ} \mathrm{N} \pm 24^{\circ}\right)$. The $S_{\text {Hmax }}$ orientation is roughly perpendicular to the topographic front throughout the basin, indicating that forces originating from the gravitational potential energy of the Alps (rather than plate boundary forces) are controlling the Molasse Basin stress field. See inset legend for details on data types, stress regime (NF = normal faulting, $S S=$ strike-slip, $T F=$ thrust faulting, $U=$ undefined), and quality ranking. Thin black lines are the trajectories of maximum horizontal stress calculated using a quality and distance weighted approach with a smoothing radius of $100 \mathrm{~km}$.

\section{GEOLOGICAL STRUCTURES}

The present-day stress orientation can be strongly influenced by existing geological structures such as faults and salt diapirs. Indeed, several authors have observed local stress variations, of the order of a few meters to kilometers near faults, fractures folds and diapirs (Figure 3; Figure 7; Bell, 1996; Yale, 2003; Tingay et al., 2005). The deflection of the stress field near geological structures is most commonly considered to result from structures acting as a mechanical discontinuity (Figure 7; Bell, 1996). For example, an 'open' or very 'weak' fracture in the subsurface will act as a free surface and be unable to sustain shear stresses. As a result, the stress field must be locally re-oriented in the vicinity of the fracture so that one principal stress acts perpendicular to the fracture. Similarly, stresses will be locally deflected or 'refracted' near the boundary between mechanical contrasts. In general, it is predicted that the maximum horizontal stress orientation will be deflected sub-parallel to mechanically 'weak' structures (e.g. salt or overpressured shale diapirs, open fractures and weak fault zones), but be deflected 
perpendicular to mechanically 'stiff' structures (e.g. cemented faults and fractures or igneous intrusives; Figure 7; Bell, 1996). The scale at which structures influence the stress field will relate to the degree of the mechanical contrast, the size of the structure and the orientation of the structure relative to the far-field stresses. Greater mechanical contrasts result in bigger deflections of the principal stress axes, whereas larger structures have a broader impact on the stress field. Small fractures or faults may influence the stress field within just a few centimeters of the structure, whereas the influence of larger structures, such as folds, diapirs and major faults, may extend tens of meters to several kilometers from the structure. However, the stress orientation will only be slightly deflected if one stress orientation is approximately perpendicular to the surface of the mechanical contrast.

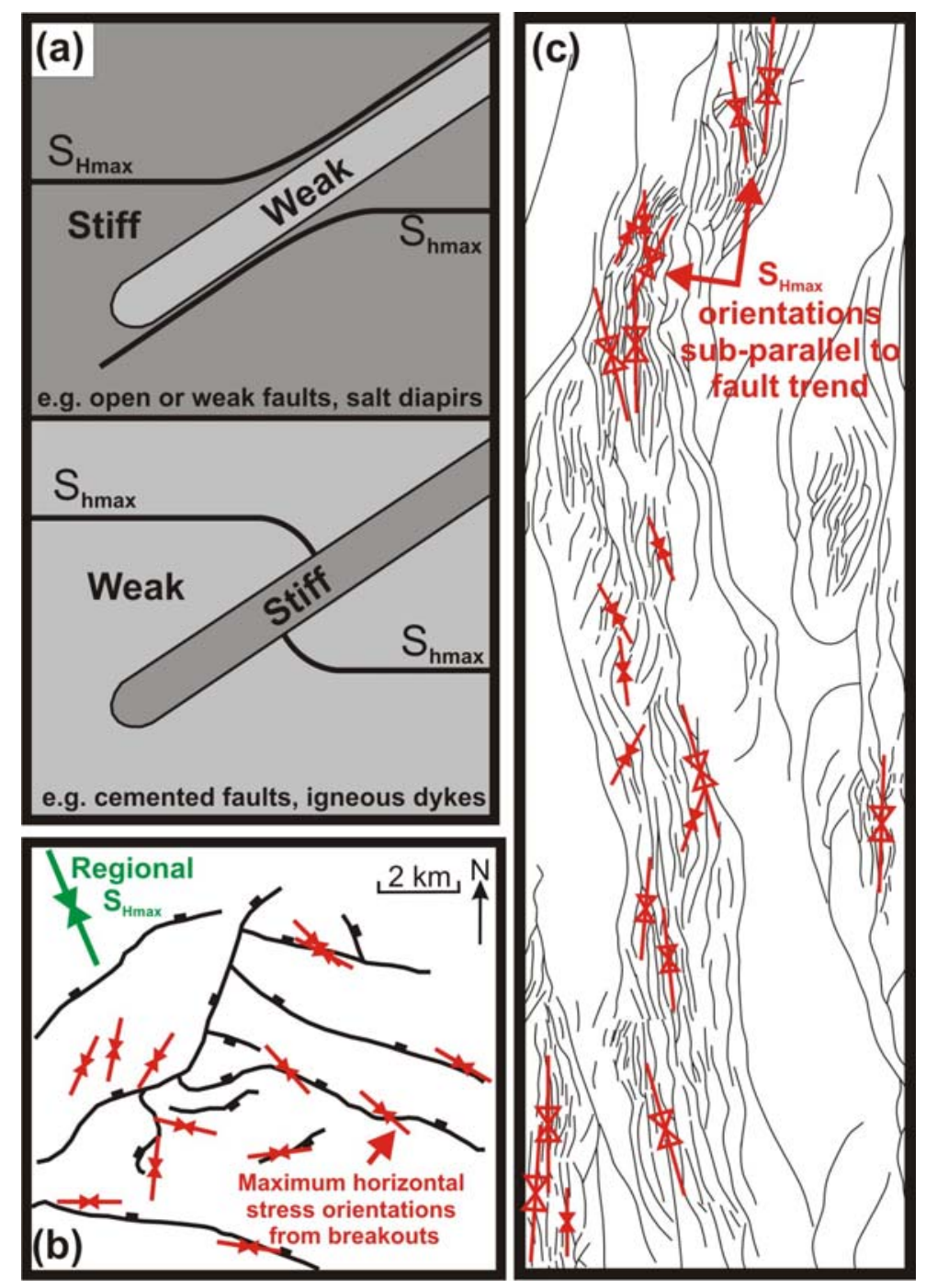

Figure 7: (a) Schematic plan view of the local rotation of $S_{H m a x}$ orientation in response to structures with contrasting mechanical properties (after Bell, 1996). The maximum horizontal stress orientation is expected to swing parallel to mechanically weak or 'soft' structures (top) and perpendicular to mechanically stiff or 'hard' structures (middle). (b) Present-day stress orientations in Witchground Graben of the northern North Sea are parallel to the strike of nearby faults and largely inconsistent with the regional stress orientation, suggesting the maximum horizontal stress orientation is being locally rotated by mechanically weak faults (after Yale, 2003). (c) $S_{\text {Hmax }}$ orientations in the Pattani Basin in the Gulf of Thailand are predominately north-south. However, the stress pattern is locally deflected between NE-SW and $N W-S E$ to be largely parallel to the trend of nearby faults. 


\section{SCALE AND SUPERPOSITION OF STRESSES}

It is important to note that scale plays a critical role in understanding stress fields in the oil patch. Discussions of the origin of stress fields commonly refer to just one or two key forces that control the observed stress field. However, stress measurements provide information on the in situ stress over a specific volume of rock (ranging from cubic kilometers for earthquakes, to cubic centimeters or meters for breakouts, hydraulic fracturing and overcoring) and the stress tensor is truly defined as the stresses acting upon a point in a continuum. Hence, when examining the origin of stress orientations, it is critical to note that the observed stress orientations and magnitudes at a point, or within a small volume of rock, are not the result of just one or two sources of stress, but result from the superposition and summation of all forces acting at scales ranging from very large (e.g. tectonic plate) to microscopic (e.g. stress concentration at grain to grain contacts; Figure 8). Table 1 summarizes the main factors controlling the state of stress from the basin- to field-scale in sedimentary basins, beginning with the largest plate boundary forces and ranging progressively down to the smaller magnitude and localized (yet often highly significant) impact of geological structures.

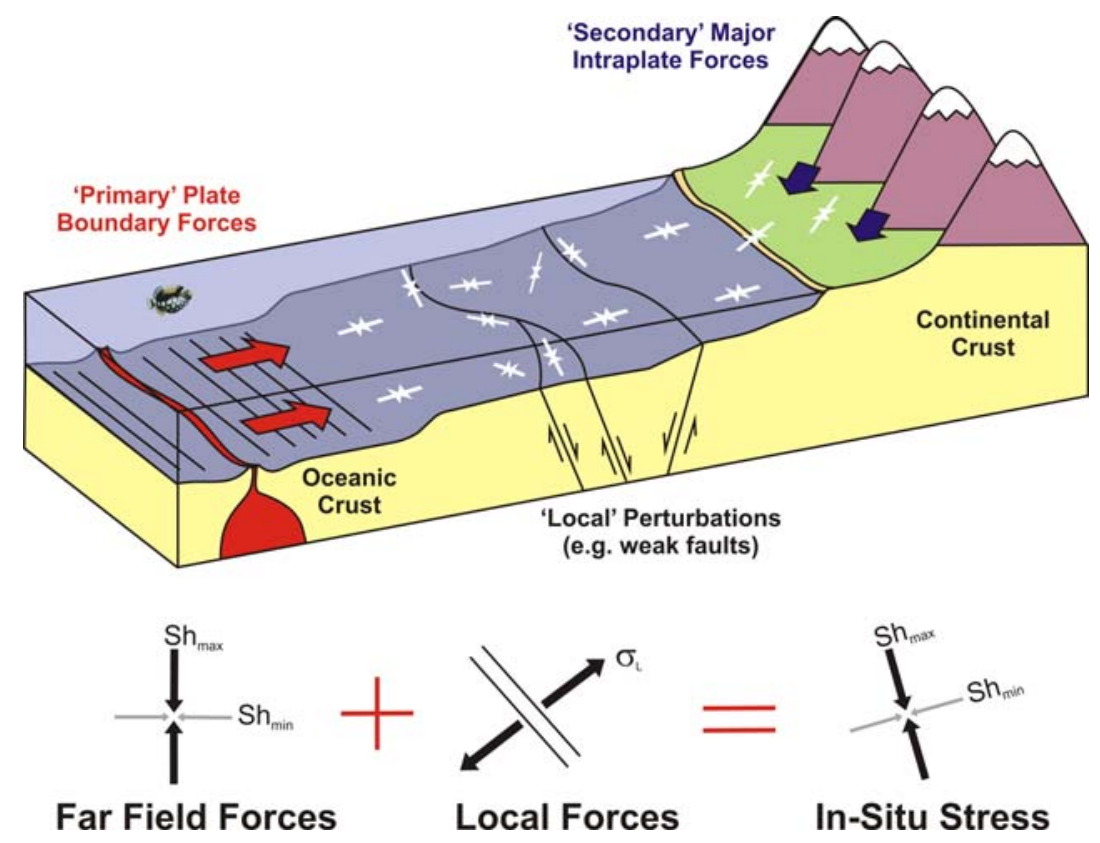

Figure 8: Schematic model of the effect of scale on stress patterns. Far-field forces provide the background regional stress pattern. However, intra-plate sources of stress will locally influence the stress pattern and may be the dominant control on the stress pattern in detached basins. Furthermore, it is important to note that the stress orientation at any point is the result of superposition and summation of all forces acting at scales ranging from thousands of kilometers (e.g. far-field forces such as ridge push) to meters (e.g. local forces such as near faults).

\section{SUMMARY}

The WSM project has compiled over 4000 datasets of present-day $\mathrm{S}_{\mathrm{Hmax}}$ orientation on over 70 sedimentary basins, providing unique insights into the origin and controls on contemporary stresses in the oil-patch. This data reveals that stresses are not simply a function of plate boundary forces and should not be assumed to be parallel to absolute plate motion. Indeed, the orientation of $S_{\mathrm{Hmax}}$ in sedimentary basins is a function of forces acting at a variety of scales ranging from large plate boundary forces, major intraplate sources of stress, basin geometry, topography and local structures (Table 1). Large far field forces often provide the dominant control on the stress orientation in old mechanically attached basins, however the presence of basal or intrabasinal detachments can isolate sedimentary sequences from far field forces and lead to locally induced stresses being dominant. 
Table 1. Summary of the main features causing or influencing stress fields in sedimentary basins and the approximate scale at which they affect the stress field.

\begin{tabular}{|c|c|c|c|}
\hline Feature & Examples & Effect & Scale \\
\hline $\begin{array}{l}\text { Plate Boundary } \\
\text { Forces }\end{array}$ & $\begin{array}{c}\text { Mid-ocean ridges, } \\
\text { continental collision zones, } \\
\text { subduction zones }\end{array}$ & $\begin{array}{c}\text { 'Primary' control on stress } \\
\text { field }\end{array}$ & $\begin{array}{l}\text { Plate to regional: 100s- } \\
1000 \text { s of km }\end{array}$ \\
\hline $\begin{array}{l}\text { Major intraplate } \\
\text { Forces }\end{array}$ & $\begin{array}{c}\text { Surface loads, isostatic } \\
\text { compensation, continent-ocean } \\
\text { transition, deglaciation } \\
\end{array}$ & $\begin{array}{c}\text { 'Secondary' control on stress } \\
\text { field }\end{array}$ & Regional: 100s of km \\
\hline $\begin{array}{l}\text { Detachment } \\
\text { zones }\end{array}$ & $\begin{array}{l}\text { Evaporites, overpressured } \\
\text { shales, low angle faults. }\end{array}$ & $\begin{array}{c}\text { Mechanically detach } \\
\text { overlying sediments from } \\
\text { primary/secondary } \\
\text { ('basement') stress field }\end{array}$ & $\begin{array}{l}\text { Basin to local scale: } \\
\text { 10s-100s of km }\end{array}$ \\
\hline Basin Geometry & Tertiary deltas, & $\begin{array}{c}\text { Regional control on stress } \\
\text { field, particularly in detached } \\
\text { basins }\end{array}$ & $\begin{array}{l}\text { Basin scale (100s of } \\
\mathrm{km})\end{array}$ \\
\hline $\begin{array}{c}\text { Major } \\
\text { Topography } \\
\text { (Mountain Belts) }\end{array}$ & $\begin{array}{l}\text { Foreland basins, back-arc } \\
\text { basins, intermontaine basins }\end{array}$ & $\begin{array}{c}\text { Gravitational forces exerted } \\
\text { due to weight of thickened } \\
\text { lithosphere }\end{array}$ & $\begin{array}{l}\text { Basin scale (100s of } \\
\mathrm{km})\end{array}$ \\
\hline \multirow{2}{*}{$\begin{array}{l}\text { Geological } \\
\text { Structures }\end{array}$} & Faults, fractures, diapirs, folds & $\begin{array}{c}\text { Rotation of stress field due } \\
\text { to mechanical contrasts } \\
\text { between units }\end{array}$ & $\begin{array}{l}\text { Local (meters to a few } \\
\text { kms) }\end{array}$ \\
\hline & Active faults & $\begin{array}{l}\text { Temporal change in stress } \\
\text { associated with seismic cycle }\end{array}$ & $\begin{array}{c}\text { Local to regional } \\
\text { depending on scale of } \\
\text { fault activity: } 1 \text { to } 100 \mathrm{~s} \\
\mathrm{~km}\end{array}$ \\
\hline $\begin{array}{c}\text { Local } \\
\text { Topography }\end{array}$ & Mountains, valleys & $\begin{array}{l}\text { Rotation of principal stresses } \\
\text { due to Earth’s surface being } \\
\text { a free surface }\end{array}$ & $\begin{array}{l}\text { Shallow regions only: } \\
\text { near surface, within } \\
\text { approximately one } \\
\text { ‘wavelength' of } \\
\text { topography }\end{array}$ \\
\hline
\end{tabular}

\section{ACKNOWLEDGEMENTS}

The World Stress Map project is a collaborative project that would not be possible without the efforts of many scientists worldwide. The full list of WSM contributors is too numerous to be given herein, however the author would like to acknowledge several individuals and organizations that have made major contributions to the WSM Project. The author is particularly grateful to Mary Lou Zoback, Mark Zoback, Peter Connolly, Jose Dirkzwager, Karl Fuchs, Richard Hillis, Scott Reynolds, Helmut Kipphan and the WSM advisory board for their major contributions and long-term support of the WSM Project. The author would also like to thank BP, RWE-Dea, Chevron, Schlumberger, Statoil, Shell, Murphy, Premier Oil, IEOC, Karasu, Petronas, PTT, Paradigm and the Egyptian Gas Company, and in particular Peter Bentham, Bob Cornell, Arnoud Defeyter, Earl Edmonds, Stephen Edwards, Paul Grech, Toby Harrold, Christian Hermanrud, Paul Hoenmans, Chris Morley and Rauf Nadirov, whom have actively supported the 'Present-day stress in Sedimentary Basins' initiative. Finally, the author would like to thank he's collaborators at the WSM project: Oliver Heidbach, Birgit Müller, John Reinecker, Andreas Barth, Blanka Sperner, Phillip Fleckenstein and Freidemann Wenzel.

\section{REFERENCES}

Aadnoy, B.S. and Chenevery, M.E., 1987, Stability of highly inclined boreholes: SPE Drilling Eng. 2, 364-374.

Ask, M.V.S., 1997, In Situ stress from breakouts in the Danish Sector of the North Sea: Mar. and Pet. Geo. 14, 231-243.

Bell, J.S., 1996, Petro Geoscience 2. In situ stresses in sedimentary rocks (part 2): Applications of stress measurements: Geoscience Canada 23, 135-153.

Finkbeiner, T., Zoback, M., Stump, B.B., and Flemings, P.B., 2001, Stress, Pore Pressure, and Dynamically Constrained Hydrocarbon Columns in the South Eugene Island 330 Field, Gulf of Mexico: AAPG Bull. 85, 1007-1031. 
Heffer K. and Lean, J.C., 1993, Earth stress orientation - a control on, and guide to, flooding directionality in a majority of reservoirs. In: Reservoir Characterization III, ed. B. Linville.

Heidbach, O., Tingay, M., Barth, A., Reinecker, J., Kurfeß, D., and Müller, B., 2008, The 2008 release of the World Stress Map: available online at www.world-stress-map.org.

Hillis, R.R. and Reynolds, S.D., 2000, The Australian Stress Map: J. Geol. Soc. London 157, 915-921.

Hillis, R.R. and Nelson, E.J., 2005, In situ stresses in the North Sea and their applications: petroleum geomechanics from exploration to development. In: Petroleum Geology: NorthWest Europe and Global Perspectives - Proceedings of the 6th Petroleum Geology Conference, eds: A.G. Doré and B. Vining. Geol. Soc., London, 551-564.

Hubbert, M.K. and Willis, D.G., 1957, Mechanics of Hydraulic Fracturing: Trans. AIME. 210, 153-166.

King, R.C., Hillis, R.R., Tingay, M.R.P., and Morley, C.K., in press, Present-day stress and neotectonic provinces of delta to deepwater fold-thrust belt systems: Insights from NW Borneo. J. Geol. Soc. London.

Reynolds, S.D., Coblentz, D., and Hillis, R.R., 2002, Tectonic forces controlling the regional intraplate stress field in continental Australia: results from new finite-element modelling: J. Geophys. Res. 107, 10.1029/2001JB000408.

Richardson, R.M., 1992, Ridge forces, absolute plate motions, and the intraplate stress field: J. Geophys. Res. 97, 11739-11748.

Roth F. and Fleckenstein, P., 2001, Stress orientations found in north-east Germany differ from the West European trend: Terra Nova 13, 289-296.

Tingay, M., Müller, B., Reinecker, J., Heidbach, O., Wenzel, F., and Fleckenstein, P., 2005, Understanding tectonic stress in the oil patch: The World Stress Map Project: The Leading Edge 24, 1276-1282.

Yale, D.P., 2003, Fault and stress magnitude controls on variations in the orientation of in situ stress. In: Fracture and in-situ stress characterization of hydrocarbon reservoirs, ed. M.S. Ameen. GSL Sp. Pub. 209, 55-64.

Zoback, M.L., 1992, First- and second-order patterns of stress in the lithosphere: the world stress map project: J. Geophys. Res. 97, 11,703-11,728. 